\title{
Qualitative monitoring of a treated wastewater reuse extensive distribution system: COD, TSS, EC and pH
}

\author{
T Manios $^{1 *}, \mathrm{E} \mathrm{Gaki}^{2}$, S Banou ${ }^{2}$, D Ntigakis ${ }^{3}$ and A Andreadakis ${ }^{3}$ \\ ${ }^{1 *}$ School of Agricultural Technology, Technological Education Institute of Crete, Heraklion 71004, Crete, Greece \\ ${ }^{2}$ Department of Technological Environmental Engineering, Technological Education Institute of Crete, Chania 71200, Crete, Greece \\ ${ }^{3}$ Water Resources Division, Department of Civil Engineering, National Technical University of Athens, Athens 15780 , Greece
}

\begin{abstract}
During a five-month summer period, samples of tertiary treated wastewater flowing in an extensive distribution system composed of storage tanks and pipes, were collected at two-week intervals from 21 different sampling points, including the exit from the wastewater treatment plant (WWTP). The WWTP producing this effluent treated wastewater from one of the most popular European tourist resorts on the north coast of the island of Crete, at the southernmost point of Greece. Crete is a semiarid region where $80 \%$ of the freshwater resources are consumed by agriculture. More than 3000000 tourists visit the island during the summer period and the average summer equivalent population treated by the plant exceeds 50000 , falling to under 5000 in the winter. The samples were analysed for chemical oxygen demand (COD), total suspended solids (TSS), electrical conductivity (EC) and $\mathrm{pH}$. The average COD and TSS in the WWTP exit were within the reuse limits for orchard irrigation, being $80 \mathrm{mg} / \ell$ and $25 \mathrm{mg} / \ell$ respectively. Both recorded higher values in the other sampling points, but still as an average below the above-mentioned limits. COD values along the distribution system presented a strong correlation with the WWTP's effluent quality, affected mainly by the condition of the collector, whereas TSS presented a completely different behaviour. EC and $\mathrm{pH}$ exceeded the optimum operation and reuse guidelines, mainly due to excessive septage in the WWTP. However, both presented a stable and predictable behaviour in correlation to the effluent quality, in terms of both distance and time, similar to that of COD. In terms of these parameters it is safe to suggest that, , achieving the required quality standards in the WWTP exit, the wastewater quality should be considered adequate for reuse for irrigation.
\end{abstract}

Keywords: wastewater; irrigation; distribution system; reuse; COD; TSS; EC; pH

\section{Introduction}

With a growing human population and continued improvement of quality of life, water resources are under stress both quantitatively and qualitatively. The world supply of freshwater is limited and threatened by pollution from various human activities. Rising demands for water to supply agriculture, industry and cities are leading to competition over the allocation of the limited freshwater resources (Gleick, 2002).

In Greece, it is estimated that water consumption is increasing by more than $3 \% /$ a.. The major water use in Greece is irrigated agriculture, and the island of Crete consumes approximately 268 $\mathrm{x} 10^{6} \mathrm{~m}^{3}$ annually (Angelakis et al., 1999; Tsanis and Naoum, 2003) for irrigation use only. The island also faces the major challenge of adequate water resources, especially during the summer when over 3000000 tourists visit the Crete (GNTO, 2005).

Given these developments, a large number of arid and semiarid countries, including those in the Mediterranean region, are considering or already applying extensive wastewater reuse schemes, mainly for irrigation purposes (Shelef and Azon, 1996; Nurizzo et al., 2001). The success and public acceptability of this practice dictates the need for maintaining uncompromising, high-quality standards in any treated effluent and reclaimed wastewater which is reused. This is particularly important for the irrigation of food crops that are eaten raw, or public parks

\footnotetext{
* To whom all correspondence should be addressed.

용 +30 2810 379456; fax: +30 2810318204 ;

e-mail: tmanios@steg.teiher.gr

Received 13 June 2005; accepted in revised form 22 September 2005.
}

and sports fields (Tanaka et al., 1998; Armon et al., 2002).

Standards for wastewater reuse in many countries have been influenced by the World Health Organisation (WHO) Health Guidelines (WHO, 1989) and the United States Environmental Protection Agency (USEPA/USAID) Guidelines (EPA, 1992). The WHO Health Guidelines focus mainly on the presence of pathogens, while the Environmental Protection Agency (EPA) also includes physiochemical parameters such as organic load $\left(\mathrm{BOD}_{5}\right.$ or $\left.\mathrm{COD}\right)$, TSS and residual chlorine concentration. The problem with treated wastewater sampling, which will eventually affect guideline establishment and monitoring, is the exact placement of the sampling point at which the quality standards must be achieved. Reuse licensing in Greece imposes quality standards on the wastewater treatment plant (WWTP) exit and not on the exact point of treated wastewater application. However, existing results have shown that the quality of treated wastewater deteriorates as it flows through distribution pipes, due to pathogen reactivation, pipe corrosion or external contamination (Shuval et al., 1973; Lindenauer and Darby, 1994; Higgins et al., 2002; Gehr et al., 2003).

In order to determine the most appropriate and reliable sampling point it is important to consider all data, whether produced in research laboratories and controlled environments or in real-life applications. The aim of this paper is to monitor such an actual application, in an extensive, operational tertiary treated wastewater distribution system, by correlating COD and TSS concentrations, as well as EC and $\mathrm{pH}$ values, with the effluent quality and downstream distance from the WWTP exit. The objective was to determine whether or not it is realistic to regard the effluent discharge point of a plant as the point where quality reuse standards should be imposed. The Port of 
Hersonissos is located $20 \mathrm{~km}$ west of Heraklion (capital of the island) on the north coast. The 20 year mean annual precipitation in the surrounding area is $792 \mathrm{~mm}$ and the mean temperature is $15.5^{\circ} \mathrm{C}$. During the summer period (April to September) the mean total precipitation is less than $100 \mathrm{~mm}$, and the temperature reaches mean values of $19.6^{\circ} \mathrm{C}$ (Hellenic National Meteorological Service - HNMS, 2005).

\section{Materials and methods}

The Port of Hersonissos has developed over the past 20 years into one of the most popular summer destinations in Europe. The permanent winter population is not more than 5000 inhabitants, dramatically increasing to over 70000 during the summer. The municipal WWTP was built on the outskirts of Hersonissos, as the first part of a two-phase plant for the whole area, and has been fully operational since June 2001.

The WWTP serves the majority of this population (approximately 50,000 person equivalent) by receiving either septage or sewage. All the effluent is reused in olive tree irrigation. This is in fact the first WWTP in Greece where 100\% reuse of the effluent in crop irrigation (and fire protection) is designated as the final discharge option. As such, all the treated wastewater produced must be used for irrigation, since any alternative solution (such as discharge into the sea) is not permitted, due to the extensive tourism. Hersonissos is famous for its crystal-clean sea and beaches (and would like to remain so).

The treatment plant includes screening, grit removal, primary sedimentation, an activated sludge bioreactor, secondary sedimentation, sand filtration and chlorination. The received septage is also treated prior to its introduction to the main treating line, through screening, grit removal and homogenisation. Disinfection is accomplished through chlorination using a concentrated (14\%) $\mathrm{NaOCl}$, which is fed automatically based on residual (closed loop) control. The system was adjusted to add 5 to $8 \mathrm{mg} / \mathrm{l}$ of chlorine to the flowing wastewater. A typical plug-flow contact basin is utilised to achieve the required contact time.

The final effluent distribution system is divided into two irrigation zones: the low irrigation zone (LIZ) which extends 0 to $80 \mathrm{~m}$ above sea level, and the high irrigation zone (HIZ), 70 to $100 \mathrm{~m}$ above sea level. The first part of each zone contains two storage tanks: the low zone irrigation tank (LZIT, with a volume of $800 \mathrm{~m}^{3}, 100 \mathrm{~m}$ above sea level) and the high zone irrigation tank (HZIT, with a volume of $220 \mathrm{~m}^{3}, 140 \mathrm{~m}$ above sea level). These two tanks are connected through a main distribution pipe to a storage tank at the exit (exit storage tank, EST) of the WWTP. Connected to the EST (with a $300 \mathrm{~m}^{3}$ volume) there is a pumping station with three pumps ( $250 \mathrm{~kW}$ overall power) supplying LZIT and HZIT through a main pipe. This main pipe is $3.2 \mathrm{~km}$ long, is made of PVC, with 16 atmospheres (atm) pressure capacity and a diameter of $300 \mathrm{~mm}$. It is covered with 0.5 to $0.8 \mathrm{~m}$ deep soil. The secondary pipe network, connecting the HZIT and LZIT with the various collectors used for the supply of effluent to the fields, is $15 \mathrm{~km}$ long, also made of PVC, with 16 atm and a diameter varying between 125 and $200 \mathrm{~mm}$. There are 45 irrigation outlets (locally known as collectors) distributed along the pipe network together with 32 fire hydrants. Figure 1 presents a diagram of the wastewater distribution system and the placement of the 18 outlets and the three tanks from which samples were taken. In total 21 sampling points were monitored.
Figure 1

Schematic representation of the distribution system and the selected sampling points (Collectors)

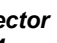

4

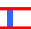

Collector

3

Collector
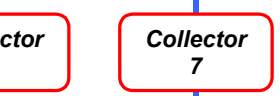

lector ector
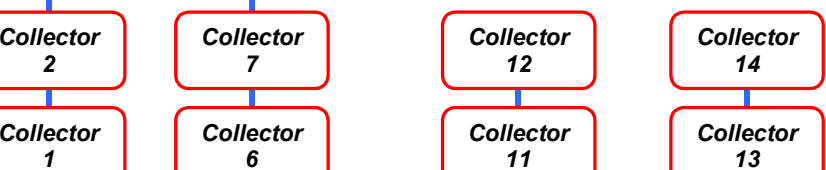

1
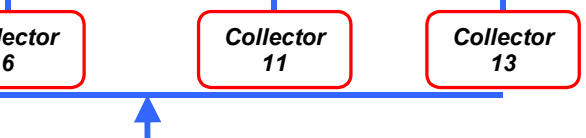

(1)

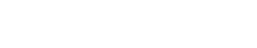

The distribution system from the treatment works to the irrigation outlets is usually managed and maintained by experienced personnel from the local Municipal Enterprise for Water Supply and Wastewater Services (MEWSWS), which is also responsible for the WWTP. The final land-crop application of the effluent is controlled by each individual farmer, and requires no technical expertise since it mimics traditional/conventional irrigation practices. Health and safety restrictions have been placed upon the farmers, who, however, do not participate in any relevant training schemes. In addition, a reuse manual was compiled and published and is distributed by the municipality to all parties to the scheme a few months before any effluent is applied to the land. Sampling took place at approximately two-week intervals for a total of 5 months starting on 19 May and finishing on 11 October 2003. This time period coincides with the main irrigation period for olive trees (early May to late September), as well as the peak of the tourist season, which starts in mid-April and ends in late October. The aim of this sampling schedule was to record possible correlations between the WWTP inflow rate and effluent quality. Figure 2 presents the average daily inflow (in $\mathrm{m}^{3} / \mathrm{d}$ ) fluctuation for each month between January 2002 and October 2003.

A portable refrigerator was used, in which the samples were placed for approximately 120 to 150 min during sampling and transportation. Plastic sterilised bottles of $0.5 \ell$ volume were used. Samples were then immediately transported to the laboratory and analysed for COD, TSS, E.C. and pH, using the methods as described in Standard Methods (1995).

\section{Results and discussion}

Electrical conductivity and $\mathrm{pH}$ values are not considered to be primary parameters in the reuse guidelines. However, EC should have a more important role in the guidelines, since it will affect and eventually alter the salinity of the irrigated land. 
Figure 2 (right)

Inflow flow rate variation with time

Figure 3 (top left) Average E.C. values in all sampling points (the bars represent standard deviation)

Figure 4 (middle left) Average E.C. value for each sampling day in all 18 collectors and the WWTP exit (effluent)

Figure 5 (bottom left) Average $\mathrm{pH}$ values in all sampling points (the bars represent standard deviation)
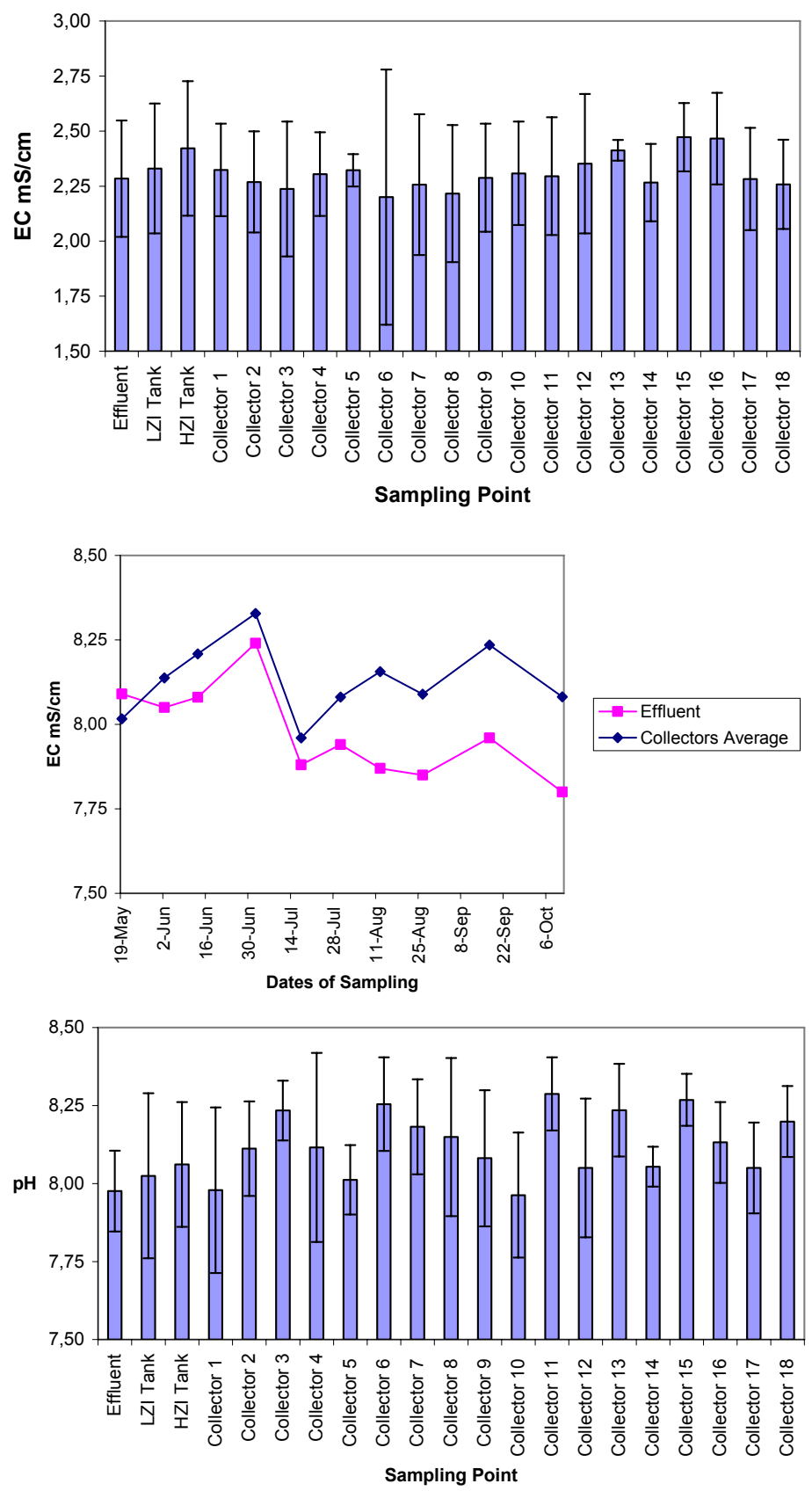

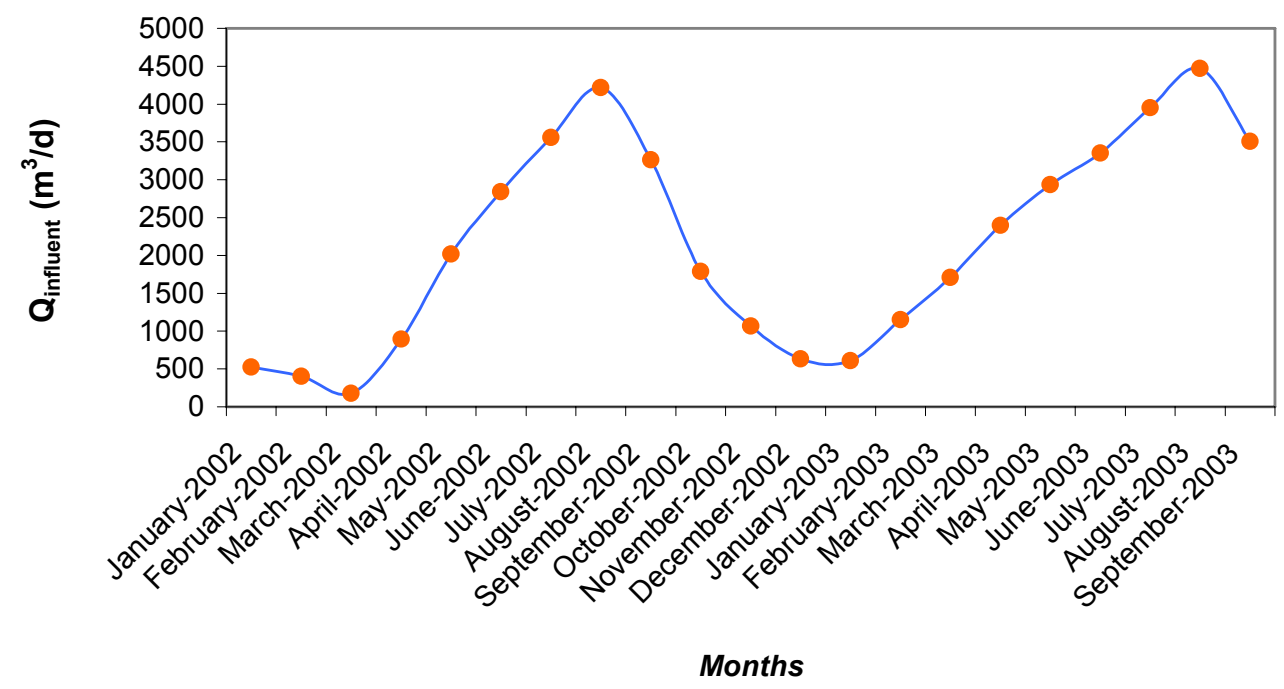

According to Mohammad and Mazahreh (2003), irrigating land for long periods with secondary treated wastewater (as in this case) results in a substantial increase in salinity. Tchobanoglous and Burton (1996), suggested that effluent with an average EC value of between 0.7 and $3.0 \mathrm{mS} / \mathrm{cm}$ should have some restrictions on use. Application of such saline effluent in an already brackish soil could accelerate its deterioration.

Figure 3 presents the average EC value for all 18 outlets, the two tanks and the exit of the WWTP. The effluent mean $\mathrm{EC}$ of $2.28 \mathrm{mS} / \mathrm{cm}$ must be considered as a problem, especially since it has a considerable effect on the values recorded in the various sampling points, as suggested by both Figs. 3 and 4. The increased EC in the effluent should be regarded as a direct effect of the WWTP septage overload during the summer period, as supported by Gaki and Banou (2004). The average value in all 18 outlets for each sampling date is closely correlated to the effluent (Fig. 4). This suggests that EC should be considered a stable quality parameter, with predictable changes related to both time and distance from the WWTP, and not substantially affected by any external contamination. In other words, the value of EC at the WWTP exit should not be expected to change substantially irrespective of the length of the distribution network.

The WWTP had an operational pH effluent standard ranging between 7.0 and 8.0 (Gaki and Banou, 2004). As shown in Fig. 5 these limits were achieved at the WWTP exit (as a mean), only to be exceeded in most other sampling points, again as mean values. As an alkaline $\mathrm{pH}$ in treated wastewater should be expected to have some effect on the soil, especially after a long application period, neutral $\mathrm{pH}$ values in the effluent are desired (Mohammad and Mazahreh, 2003). The increase of the mean values in most outlets, compared to those of the effluent, is not substantial and can only be explained as a result of continuous oxidation of organic matter further down the WWTP's exit. As with EC, $\mathrm{pH}$ values prove to be very closely correlated with the effluent values as is shown in Fig. 6, allowing $\mathrm{pH}$ to be considered as a stable and predictable quality parameter, based on the effluent values..

The reuse quality limits for the surface irrigation of orchards (e.g. olive tree cultivation) suggested by the EPA are $80 \mathrm{mg} / \ell$ of COD and $30 \mathrm{mg} / \ell$ of TSS. Similar operational limits of the WWTP are recorded in the relevant 


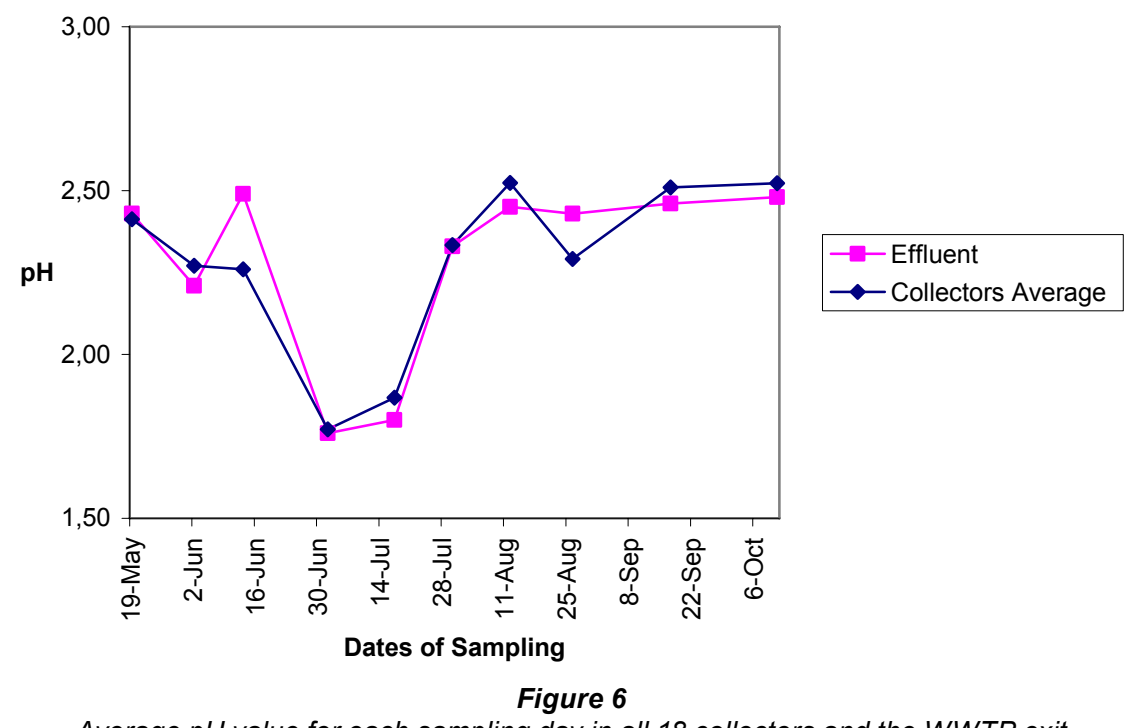

Average $\mathrm{pH}$ value for each sampling day in all 18 collectors and the WWTP exit (effluent)

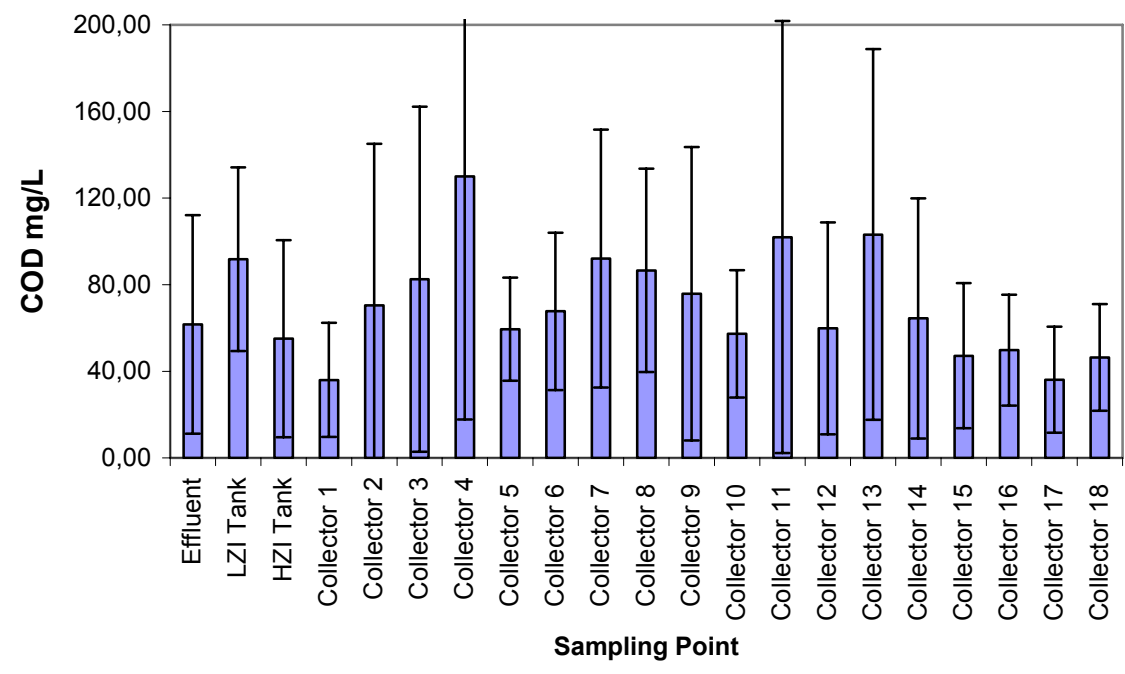

Figure 7

Average $C O D$ values in all sampling points (the bars represent standard deviation)

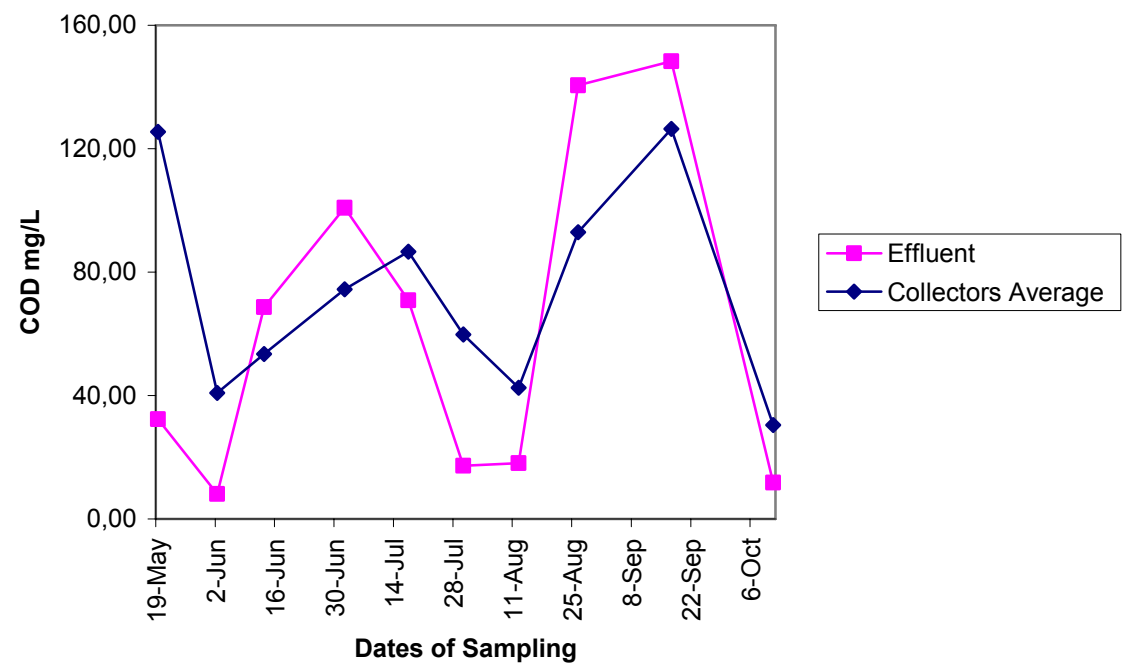

Figure 8

Average COD value for each sampling day in all 18 collectors and the WWTP exit (effluent) environmental operation licence $(80 \mathrm{mg} / \ell$ COD and $25 \mathrm{mg} / \ell \mathrm{TSS})$. In three out of the ten samplings, COD in the effluent exceeded the limit set by the operational and the EPA reuse guidelines (Figs. 7 and 8). This should be considered an acceptable result in any WWTP, since activated sludge is a treatment system which can be affected by a variety of parameters, such as excessive septage reception. According to Gaki and Banou (2004), the WWTP was obliged to receive approximately $200 \%$ more septage on a daily basis during the summer than it was originally designed for. The MEWSWS of Hersonissos considered ceasing to accept any septage during the high season (July and August) in order to improve the effluent. Nevertheless, the fact that those excessive values occurred during a period of lower inflow (May and end of August, beginning of September), indicates that those measurements may have recorded a random and isolated incident and not the overall situation within the WWTP

Two additional conclusions can be drawn from Figs. 7 and 8. First, COD values along a distribution pipeline seem to be affected mainly by the effluent value. Figure 8 in particular gives a rather close correlation of the average COD value with time to that of the effluent in all 18 collectors. This should be considered a reasonable and expected result. Corrosion and external contamination contribute to and increase (Fig. 7) the average value of COD in comparison with the effluent in almost all 18 collectors. Nonetheless, this addition of acidically oxidised substances is small in relation to those provided by the effluent, resulting in the second conclusion. If there is no large and easily identifiable external contamination along a reuse distribution pipeline such as this, then the COD variations should be considered predictable and short-range.

As far as TSS (Figs. 9 and 10) are concerned, the effluent recorded values of very good quality with an average of $5 \mathrm{mg} / \mathrm{l}$ and on only one occasion above $30 \mathrm{mg} / \mathrm{l}$. In most cases, the TSS value was almost zero. These good quality values were also recorded at the other sampling points, where the standard deviation was, however, significant. A closer evaluation of both figures indicates that the important characteristic of TSS is the fact that, even though in general the values are within the required limits, specific collectors present specific problems. For example, Collector 4 records the highest value of $316 \mathrm{mg} / \ell$ in September, whereas the collectors before and after (according to Fig. 1) recorded values of 0.0 and $5.0 \mathrm{mg} / \ell$ 
respectively. If this value were related to problems with the WWTP, similar values should have been recorded in both those collectors. That was not the case.

This strongly indicates that TSS is a parameter easily affected by conditions at the sampling point. Corrosion and external contamination should be considered the main reasons for such phenomena. Contrary to the COD, the low TSS values of the effluent expose this parameter far more to local circumstances and especially corrosion, which was a frequent problem in the collectors. It may be suggested that the vulnerability of TSS to change under external circumstances makes such quality parameters neither reliable nor predictable, as is the case with indicative micro-organisms (Gaki and Banou, 2004).

\section{Conclusions}

COD, TSS, EC and pH should be considered of secondary importance as wastewater reuse standards compared to pathogen indicators. It is, however, a requirement to determine the correlations between these parameters and the possible presence of pathogens of anthropogenic origin. As a result all suggestions presented here should be additionally supported by measurements and analyses regarding micro-organisms.

Three (COD, EC and $\mathrm{pH}$ ) out of the four (with TSS) physiochemical parameters, used to evaluate this extensive wastewater reuse distribution system, showed that they are not easily affected by either the distance or the time gap between a remote location and the exit of the WWTP. This conclusion supports the idea of evaluating and imposing reuse quality guidelines?criteria at the exit of a WWTP. This concept is additionally supported by the fact that all three parameters recorded values in the various outlets which were very closely correlated to the effluent value (see Figs. 4, 6 and 8) on the specific sampling day.

TSS is the only factor which differs substantially from the other three parameters. The values in the various outlets on different sampling days were significantly higher compared to the effluent values at the exit, whereas, as shown in Fig. 10, there was no correlation between the effluent mean value and the outlet's mean value. This behaviour indicates the risk that the required limits may have been achieved in the effluent and then completely overruled a few meters $(10$ or $100 \mathrm{~m})$ down the pipeline.

However, is not very easy to evaluate how TSS variation affects the safety of the application since we have no comparable data from a freshwater irrigation system. Corrosion of any metal parts used in the system could have occurred in any water pipe. It could be supported that corrosion is enhanced by salinity, measured here as EC, but still it cannot be established how that could affect or even threaten the health of the farmer or the consumer. Therefore, and according to the results presented here, it could be suggested that complying with the quality standards set for physiochemical parameters such as $\mathrm{pH}, \mathrm{EC}, \mathrm{COD}$ and TSS, for effluent discharges at the exit of any WWTP may be considered as adequate.

The results of this study are of global interest for a number of reasons, primarily because such complicated and extensive wastewater reuse distribution and application systems are in operation in a number of countries, all over the world. The information presented here will assist those responsible to operate any such facilities, to understand, the potential problems, weak

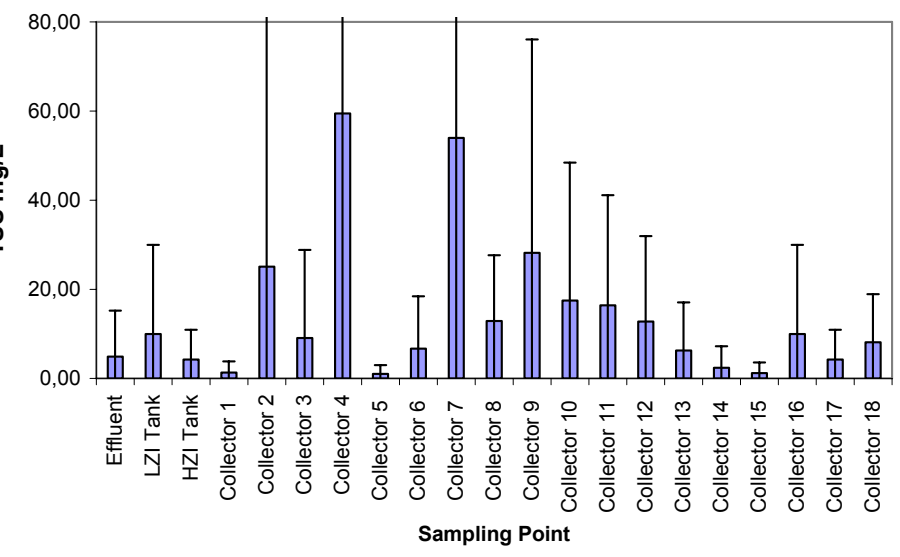

Figure 9

Average TSS values in all sampling points (the bars represent standard deviation)

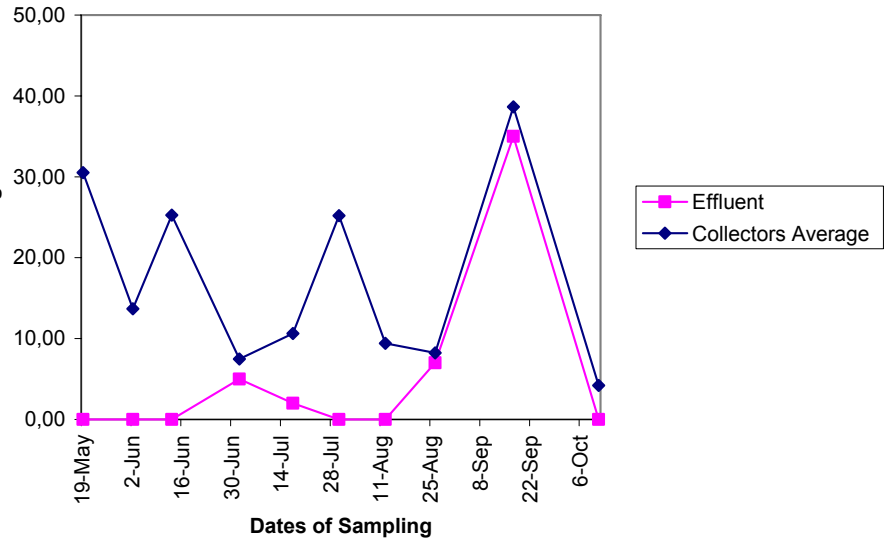

Figure 10

Average TSS value for each sampling day in all 18 collectors and the WWTP exit (effluent)

points and risks of their own their own systems better. Secondly, it presents an alternative monitoring practice, which can be applied in all similar systems and will provide far more accurate results. Finally, through the results presented here it was shown that if good, stable and effective wastewater treatment is achieved then wastewater reuse becomes increasingly safe. All problems with reuse are directly related to the level of treatment.

\section{Acknowledgements}

We would like to thank the President of the MEWSWS of Hersonissos, Mr Emmanouil Tsagarakis, for his assistance in the completion of this work.

\section{References}

ANGELAKIS AN, MARECOS DO MONTE MHF, BONTOUX L and ASANO T (1999) The status of wastewater reuse practice in the Mediterranean basin: need for guidelines. Water Res. 33 22012217.

ARMON R, GOLD D, BRODSKY M and ORON G (2002) Surface and subsurface irrigation with effluents of different qualities of Cryptosporidium oocysts in soil and on crops. Water Sci. Technol. 46 115122. EPA (1992) Guidelines for Water Reuse. Environmental Protection Agency USA /625/R-92/004, USA.

GAKI EA and BANOU S (2004) Qualitative Monitoring of Treated Wastewater Reuse Extensive Distribution System. Graduation Thesis, TEI of Crete, Greece. 
GEHR R, WAGNER M, VEERASUBRAMANIAN P and PAYMENT P (2003) Disinfection efficiency of peracetic acid, UV and ozone after enhanced primary treatment of municipal wastewater. Water Res. 37 4573-4586.

GLEICK PH (2002) The World's Water: The Biennial Report on Freshwater Resources. Island Press, Washington, USA.

GNTO (2005) Greek National Tourism Organization, March 2005, WWW.gnto.gn.

HIGGINS J, WARNKEN J, SHERMAN PP and TEASDALE PR (2002) Survey of users and providers of recycled water: quality concerns and directions for applied research. Water Res. 36 5045-5056.

LINDENAUER KG and DARBY JL (1994) Ultraviolet disinfection of wastewater: Effect of dose on subsequent photoreactivation. Water Res. 28 805-817.

MOHAMMAD MJ and MAZAHREH N (2003) Changes in soil fertility parameters in response to irrigation of forage crops with secondary treated wastewater. Commun. Soil Sci. Plan. 34 1281-1294.

HNMS (2005) Hellenic National Meteorological Service, www.hnms.gn

NURIZZO C, BONOMO L and MALPEI F (2001) Some economic considerations on wastewater reclamation for irrigation, with reference to the Italian situation. Water Sci. Technol. 43 75-81.
STANDARD METHODS (1995) Standard Methods for the Examination of Water and Wastewater (19 ${ }^{\text {th }}$ edn.). Published jointly by: American Public Health Association, American Water Works Association, and Water Environment Federation, Washington DC

TANAKA H, ASANO T, SCHROEDER ED and TCHOBANOGLOUS G (1998) Estimating the safety of wastewater reclamation and reuse using enteric virus monitoring data. Water Environ. Res. 70 9-51.

TCHOBANOGLOUS G and BURTON FL (1996) Wastewater Engineering: Treatment, Disposal and Reuse (3rd edn.). Metcalf and Eddy, Inc.: San Francisco, California, USA.

TSANIS IK and NAOUM S (2003) The effect of spatially distributed meteorological parameters on irrigation water demand assessment. Adv. Water Resour. 26 311-324.

SHELEF G and AZON Y (1996) The coming era of intensive wastewater reuse in the Mediterranean region. Water Sci. Technol. 33 115-125.

SHUVAL HI, COHEN J and KOLODNEY R (1973) Re-growth of coliforms and fecal coliforms in chlorinated wastewater effluent. Water Res. 7 537-546.

WHO (1989) Health Guidelines for the Use of Wastewater in Agriculture and Aquaculture. World Health Organization, Technical Report Series 778. Geneva, Switzerland. 